\title{
Construction of Distribution System of Coronavirus Based on Talmud Bankruptcy Distribution
}

\author{
Mengdian Hong ${ }^{1, \dagger}$ Ruoying $\mathrm{Li}^{2,{ }^{, \dagger}}$ Peiran $\mathrm{Xie}^{3,,{ }^{3, \dagger}}$ \\ ${ }^{1}$ Beijing Jiaotong University, School of Economics and Management, No. 3 Yard, Shangyuan Village, Haidian \\ District, Beijing, 100044 \\ ${ }^{2}$ Dauntseys School, West Lavington, Devizes, Wiltshire, SN104HE \\ ${ }^{3}$ Jimei University, School of Finance and Economics, No. 78, Shigu Road, Jimei District, Xiamen, 361021 \\ ${ }^{*}$ Corresponding author. Email: 201821063088@jmu.edu.cn \\ These authors contributed equally.
}

\begin{abstract}
At present, the world is suffering from COVID-19, and many countries do not have the conditions to develop a vaccine. Countries that are without the COVID-19 vaccine are still at risk of a worsening epidemic and potential sequelae, people are dying because of inadequate medical resources and medical technology, global distribution of vaccines is therefore imperative. Consequently, the equitable distribution method of vaccines from countries that can produce them to other countries would be a top priority for stabilizing the epidemic worldwide. In order to develop an equitable vaccine distribution scheme, we use literature research method, model analysis method and comparative analysis method. After searching the data and literature, we find a case in the Talmud based on the principle of contested garment, the Talmud Bankruptcy problem. A complete and fair vaccine distribution plan according to the dispute overcoat principle is then made according to the contested garment principle. At the same time, through the comparison with the proportional distribution method, the advantages of the contested garment principle in highlighting fairness can be more prominent. In the discussion section, we show the various factors that influence the distribution of COVID-19 vaccine, encompassing economic and cost factor, political and international relationship factor, priority problem and demographic factor as well as science and technology factor. The model allocation method that we choose cannot consider too many of these realistic factors, but they would more or less affect the final vaccine allocation results. Fair distribution method for new vaccine research can be provided to producing-vaccinecountries a certain consideration that how to distribute surplus vaccine to other countries, also can arouse the attention for fair distribution of vaccine of other relevant personage and organization, accelerate the development and research of more realistic, more feasible vaccine distribution system and their implementation, distinctly promote the outbreak of stability in the world.
\end{abstract}

Keywords: Coronavirus (COVID-19), Vaccine distribution, Talmud bankruptcy problem, Influencing factors.

\section{INTRODUCTION}

At the start of 2020, an unexpected highly contagious epidemic, coronavirus (COVID-19), swept across the globe. People who are infected by the COVID-19 might experience some respiratory symptoms with different degrees (mild to moderate and serious), at the same time, a great number of asymptomatic cases come to light and massive patients had recovered without receiving a treatment that is welltargeted to the disease. The total cases of COVID-19 have reached $170,157,408$ so far, and the deaths induced by this pandemic have been up to $3,538,083$ [1]

After the breakout of COVID-19, World Health Organization (WHO) attached great importance to the prevention of continuous infection, and governments of countries all over the world limited the number of flights and even placed cities on lockdown, trying to reduce the number of trips and chance of gathering. Through a year of hard work, the situation of the coronavirus epidemic has been moving towards stability, and the appearance of new cases has been reported 
slowed down. Governments are making efforts to arrange the development and research of COVID-19 vaccines, but most of them fail [2]. The wealthier countries have a higher probability of developing a successful vaccine because they have enough professionals and investment to promote the project [2]. In order to accelerate the development and scale production of the vaccine, ensure the equitable accessibility of COVID-19 vaccine for all countries, and guarantee that the vaccine is available for countries that need them most, the COVAX pillar [2], which is a global coalition aimed to overcome the pandemic, is funded. At present, there are 17 vaccines [3] being offered to the general population, China (584 million), America (291 million), India (201 million) and Spanish (65.3million) as well as England (62.7 million), are the five countries that most of the citizens have enjoyed the benefit of being vaccinated [4].

Currently, the most concentrated issue is that how to distribute the vaccine fairly and secure the supply of the COVID-19 vaccine to all nations. Recorded by the COVID-19 live update on the Worldometers (a website) [1], due on the 29th May 2021, India (9816), Thailand (4803), Ukraine (3096), and Mexico (3058) experience the highest increased case in the world, all of which are higher than 3000 cases for one day. Among them, India and Mexico are also suffered from a high number of new deaths, which are 128 and 411 respectively. These countries are not provided with enough amount of vaccine so the method of distributing COVID-19 vaccine is still waiting to be improved to meet people's need based on the principle of fairness. The proportion of people who have been vaccinated and finished the whole process of vaccination only occupied 5.3\% [4] of the total population in the world, indicating that there is still a great effort needed to be taken by countries and WHO to end the pandemic.

After spending lots of time searching for information on distributing the COVID-19 vaccine, we found that there are few articles establishing an integrated, detailed scheme for allocating the coronavirus vaccine. The supply chain of COVID-19 vaccine is still commanded by the countries that had developed them successfully. But nations that are in crisis had not developed their own vaccine still cannot get enough provision of medical aid, leading to a constant death rate and reports about detection of the mutated virus. Most articles [5] [6] [7] are focusing on the origin of virus, the specular treatment needed to be done for those critical cases as well as the greatest prevention way for COVID-19, but there are few articles being able to put forward a way of distribution which can achieve command agreement and provide an elaborate, impartial plan.

We are firstly going to view articles and reports about the worldwide circumstances and analyse the summarized and current statistics (including the total cases, countries, vaccinated proportion, and death rate) from the online database, trying to encapsulate the overall conditions by simplified words and with the assistance of several diagrams where they are needed. In this case, the data that will be required in the next stage of research will be prepared and available in any time. Secondly, a reasonable basis will be set to support the method of the COVID-19 vaccine, and the weight of each factor will be decided. Thirdly, according to the model found, we will input the data of each country in it to exhibit the exact quantity of vaccine that each of them can receive grounded on the statistics that we have taken from an exact date. Through this process, we will try our best to guarantee the fairness of the distribution way, taking as most as possible elements into account to display a coherent result.

\section{METHODOLOGY}

In view of this topic, we will use the following three specific methods to study on and explain the construction of distribution system of vaccine.

\subsection{Literature Research Method}

Literature research method is an approach to obtain data through investigation of literature according to certain research purposes or topics, so as to comprehensively and correctly understand and master the problem to be studied.

S Guiasu revisited some Game theory concepts about the ancient problems of bankruptcy, Contested Garment, and rights arbitration comprehensively and systematically, which is inspired our group a lot [8]. His study shows us how the bankruptcy problem and Contested Garment work with words and tables. Joe Malkevitch also found the same feasible way to Resolve Bankruptcy Claims [9]. Nir Dagan and Oscar Volij used mathematical formulas and calculations to prove the principle [10]. Through the reading of these papers, we have known the principle and found it quite practical. Therefore, an excellent thought of the construction of vaccine distribution would be given by us according to the theory.

To get a better understanding of the current situation of COVID-19 around the world, we go to the official websites of the WHO and some countries to get data on confirmed cases, deaths, and vaccinations. These official figures and data are of great significance to us in making an allocation plan.

M. Yazdian applys the theory to groundwater sustainability to develop a non-cooperative optimal management scenario in shared groundwater resources under water bankruptcy conditions [11]. Considering the uncertainty of railway rescue, Tang used the Talmud bankruptcy distribution for fuzzy demand of the 
accident point between resource scheduling [12]. From the perspective of urgent rescue, Zhang summarized the research an equitable distribution of three different models, proves that the three models all can achieve their fair results, and draw a conclusion [13].

As for vaccine distribution, the supply and demand imbalance make this topic quite similar to emergency resource scheduling. Their studies are very valuable for reference and help the outline o our construction of vaccine distribution gradually became clear. And their research methods have also been used to verify the effectiveness and advantages of our vaccine distribution in this paper.

\subsection{Model Analysis Method}

Model method is a scientific method to realize the purpose of a prototype by building and analyzing the research model. For those object systems which cannot be studied directly, we can study and understand the prototype indirectly by designing, constructing, and analysing the model similar to the prototype.

This paper introduced a model called "the bankruptcy problem from the Talmud [8]" and contested garment principle as a basis for research. Knowing how the model works give this paper a sample to help the advance of further study of vaccine distribution.

This model is not just about the allocation for the sake of distribution. To some extent, it is fair and protects vulnerable people. The proof will be given later.

According to this model, we give a specific vaccine distribution plan which needs an official organization or institution to execute it. We know that immunization walls can only be built if $70 \%$ of the world's population is vaccinated. So rich or developing countries should be allocated vaccines. This model is based on population, which can be used to distribute more vaccines to countries with large populations under the circumstance of insufficient vaccines, and at the same time protect the vaccine quantity of countries with small populations.

\subsection{Comparative Analysis Method}

Comparative analysis approach, also known as Contrastive method, is through comparing two indicator data, comparing the numerical sizes to show and explaining the research object, the level of high and low, speed fast or slow, and all kinds of relationship coordination.

Firstly, inspired by M. H. Tsay and C. H. Yeh [14], we make a longitudinal comparison of the plans, which are on the basis of the contested garment principle and the traditional proportional distribution principle. By comparing figures and data of the Talmud distribution plan and the traditional proportional distribution plan, we prove the superiority of our distribution plan. It is fairer and can really protect vulnerable people in a way.

Then, we will also do a horizontal comparison of the countries in our model to figure out which kind of distribution is better for different countries that are under different circumstances and draw some conclusions.

\section{RESULTS}

\subsection{The Principle of Contested Garment}

The principle of contested garment (PCG) is described as "dividing the controversial assets equally so that every player gets the same amount in controversial assets," and this principle ensures every creditor's minimum gain [15]. Assume that the total assets available for distribution are $E$, the claim amount for each creditor is $d$, the actual income for each creditor is a, and the claim amount for creditor 1 is less than creditor 2 , that is, $d 1<d 2$.

If the total assets are less than creditor 1's claim amount, that is $0<E<d 1$, both creditors have ownership of these assets, then each of them will get $\frac{1}{2} E$. If the total assets are bigger than creditor 1's claim amount but less than creditor 2's claim amount, that is $d 1<E<d 2$, creditor 1 have no ownership on the amount bigger than $d 1$, and the controversial assets are d1, so:

$$
\begin{gathered}
a 1=\frac{1}{2} d 1 \\
a 2=\frac{1}{2} d 1+E-d 1=E-\frac{1}{2} d 1
\end{gathered}
$$

Suppose the total assets are bigger than creditor 2's claim amount but less than both creditors' claim amount. In that casemount, that is $d 1<d 2<E<d 1+d 2$, the non-controversial part will give to each creditor, and the rest controversial assets will be divided equally. So, creditor 1 get $E-d 2$, creditor 2 first gets $E-d 1$, and the rest assets are $E-(E-d 2)-(E-d 1)=d 2+$ $d 1-E$. At last,

$$
\begin{aligned}
& a 1=(E-d 2)+\frac{(d 2+d 1-E)}{2}=\frac{E+d 1-d 2}{2} \\
& a 2=(E-d 1)+\frac{(d 2+d 1-E)}{2}=\frac{E+d 2-d 1}{2}
\end{aligned}
$$

When the total assets are greater than the sum of creditors' debts, the supply exceeds the demand and the distribution is not disputed. So, we will not discuss the use of this principle in this case. 


\subsection{The Comparison of the Principle of Contested Garment and the Proportional Distribution}

The proportional distribution is to divide assets $\mathrm{E}$ based on the ratio of $d 1: d 2$ proportionally to creditor 1 and creditor 2 , that is $a 1=\frac{d 1}{d 1+d 2} E$ and $a 2=\frac{d 2}{d 1+d 2} E$.

According to the above mathematical description of PCG and the proportional distribution, a model as shown in Figure 1 is drawn.

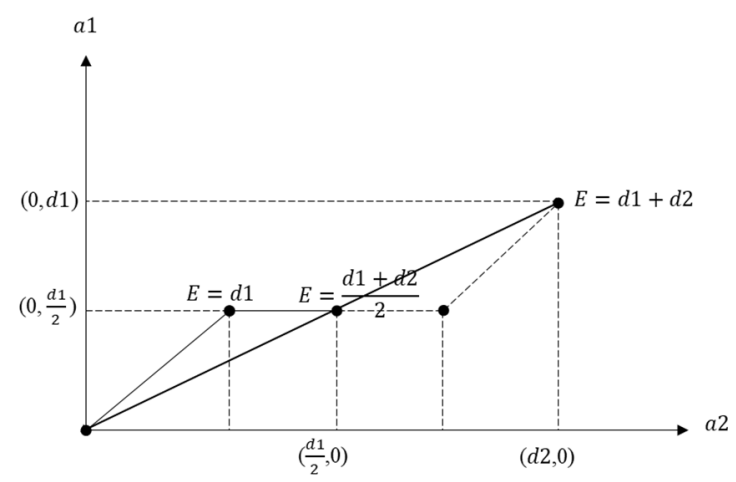

Figure 1 The principle of contested garment.

When applying PCG, before $E=d 1$, the income of both creditors is the same, and after $E=d 1$, the income is different, so this point is called the "first cutoff point" $\left(E^{*}\right)$.

When $E=(d 1+d 2) / 2$, the result of applying PCG and the proportional distribution is same, so this point is called the "second cut-off point" $\left(E^{* *}\right)$; before $E^{* *}$, creditor 1 gets more by using PCG, which can be considered a victory for the underdog; after $E^{* *}$, the reverse can be seen as a victory for the stronger.

When $E=d 1+d 2-d 1 \times \frac{2}{2}$, the loss for them is the same, and when $\mathrm{E}$ increases later, the increased amount is divided equally to them, so this point is called the "third cut-off point" $\left(E^{* * *}\right)$.

$E^{*}$ ensures the application of PCG. $E^{* *}$ reflects the protection of the weak in the case of insufficient resources, that is, the weak's income is more by using PCG than by using proportional distribution. $E^{* * *}$ guarantees the protection of the interests of the stronger in the case of more available resources.

\subsection{Talmud Bankruptcy Distribution}

A rationale for " $\mathrm{n}$ creditors' assets distribution" solutions is given in terms of the Talmudic principle of equal division of the contested garment [15]. Generally, all creditors are numbered $\{1,2, \ldots, n\}$, the property claimed is sorted in order from least to most, $c[1] \leq$ $c[2] \ldots \leq c[n]$, and the total property to be distributed is $\mathrm{E}$. The property declared by the creditors is $c[1,2, \ldots, n]=c[1]+c[2]+\cdots+c[n]$.
According to the meaning of every cut-off point, we can get:

$$
\begin{gathered}
E^{*}=c[1] \times n / 2 \\
E^{* * *}=c[1,2, \ldots, n]-c[1] \times n / 2
\end{gathered}
$$

Creditors from 1 to $n$ can get $x[1], x[2], \ldots, x[n]$, so that vector $\mathbf{x}(\mathbf{E})=(\mathbf{x}[\mathbf{1}], \mathbf{x}[\mathbf{2}], \ldots, \mathbf{x}[\mathbf{n}])$ is the allocation plan of E.

when $\mathrm{E}<E^{*}$, the assets are the controversial assets, so the allocation plan is $\mathbf{x}(\mathbf{E})=(\boldsymbol{E} / \boldsymbol{n}, \boldsymbol{E} / \boldsymbol{n}, \ldots, \boldsymbol{E} / \boldsymbol{n})$.

When $E^{*}<E \leq E^{* * *}$, the problem of n players can be solved by dividing these plays into two groups $\{1\}$ (the least claim one) and $\{2,3, \ldots, n\}$. After calculation these two groups by using PCG, then do the second calculation of group $\{2\}$ (the least claim creditor now) and $\{3,4, \ldots, n\}$. At last, do the calculation between $\{n-1\}$ and $\{n\}$.

When $E^{* * *}=E$, every creditors loss is the same. If the corresponding allocation plan is $\mathbf{x}\left(\mathbf{E}^{* * *}\right)=$ $(\mathbf{x}[\mathbf{1}], \mathbf{x}[\mathbf{2}], \ldots, \mathbf{x}[\mathbf{n}])$, when $E^{* * *}<E$, the incremental part $d=E-E^{* * *}$ will be equally divided by these $\mathrm{n}$ creditors. In conclusion, when $E^{* * *}<E$, the allocation plan is $\mathbf{x}(\mathbf{E})=(\mathbf{x}[\mathbf{1}]+\boldsymbol{d} / \boldsymbol{n}, \mathbf{x}[\mathbf{2}]+\boldsymbol{d} / \boldsymbol{n}, \ldots, \mathbf{x}[\mathbf{n}]+$ $d / n)$.

\subsection{Data Analysis}

The population of different countries varies a lot, so do the vaccine numbers of different counties. It will be complex to analyze the real situation if we use the real population numbers. Also, economy power and diplomacy vary in different countries. Therefore, we simplify the real situation by positing that there are five countries globally and the vaccines are distributed only by WHO, so that the revelation of applying different methods can be shown clearly. The demand for vaccine numbers for each country is shown in Table 1 below. And the numbers placed in the table are random but sorted from least to most, which represent various population of different countries in the world

Table 1. the demand of vaccine numbers for each country

\begin{tabular}{|c|c|c|c|c|c|}
\hline Country & $\mathrm{V}$ & $\mathrm{W}$ & $\mathrm{X}$ & $\mathrm{Y}$ & $\mathrm{Z}$ \\
\hline $\begin{array}{c}\text { Demand of } \\
\text { vaccines } \\
\text { (million } \\
\text { doses) }\end{array}$ & 100 & 200 & 300 & 400 & 500 \\
\hline
\end{tabular}

The total demand (D) for these countries is 150 million doses. It is important to note that the Talmud bankruptcy distribution premise is met if the available amount of vaccine is less than the total demand, so we only discussion the situation when available amount 
$\mathrm{E}<150$ million here by using the Talmud distribution plan (TD) and the traditional proportional distribution plan (TP). According to the methods of TD and TP, the allocation results are listed in figures 2-6 and the appendix.

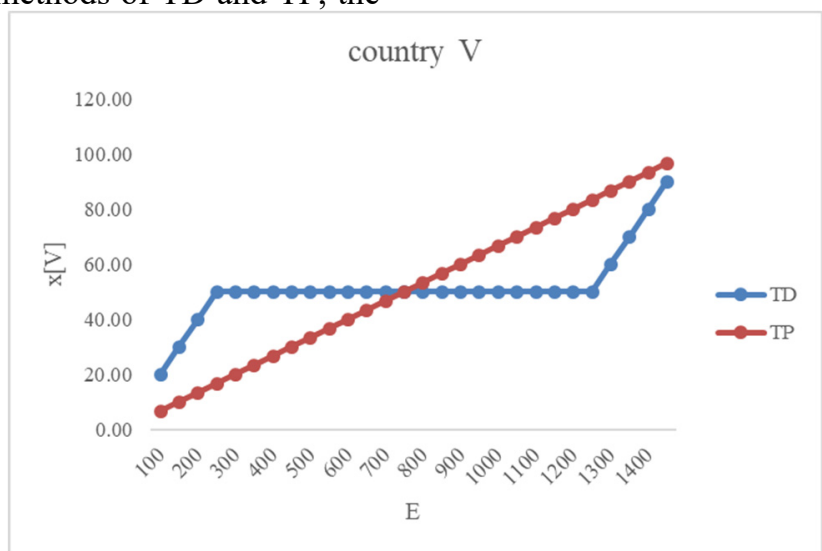

Figure 2 The available amount of vaccine for country V.

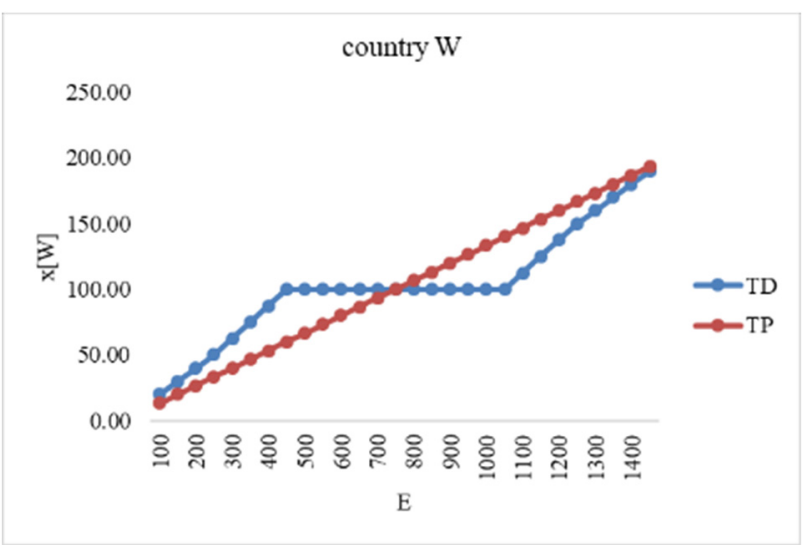

Figure 3 The available amount of vaccine for country W.

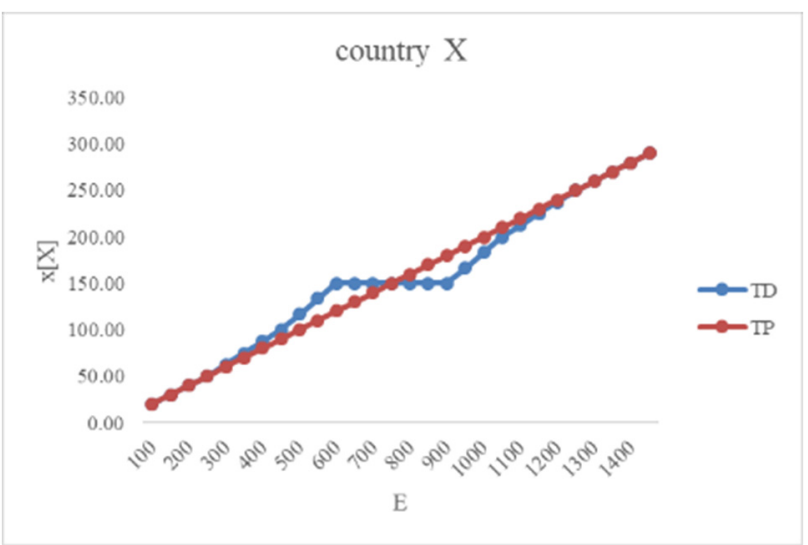

Figure 4 The available amount of vaccine for country X. 


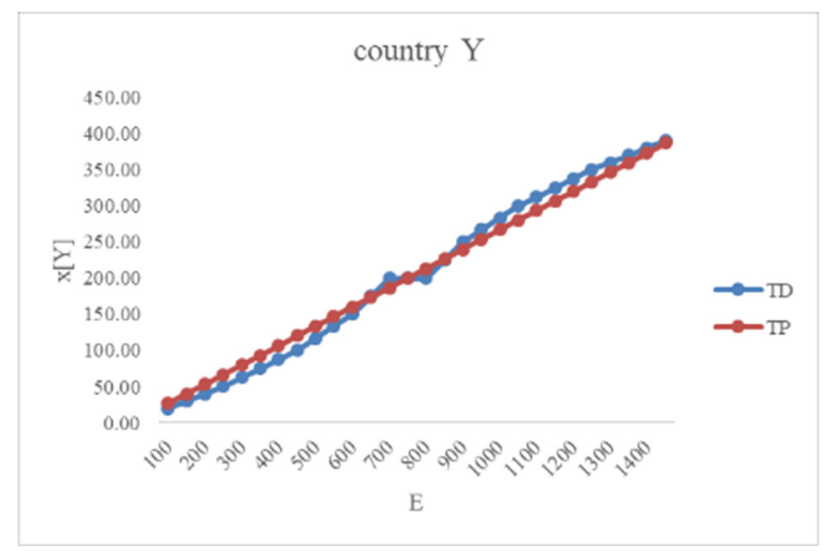

Figure 5 The available amount of vaccine for country Y.

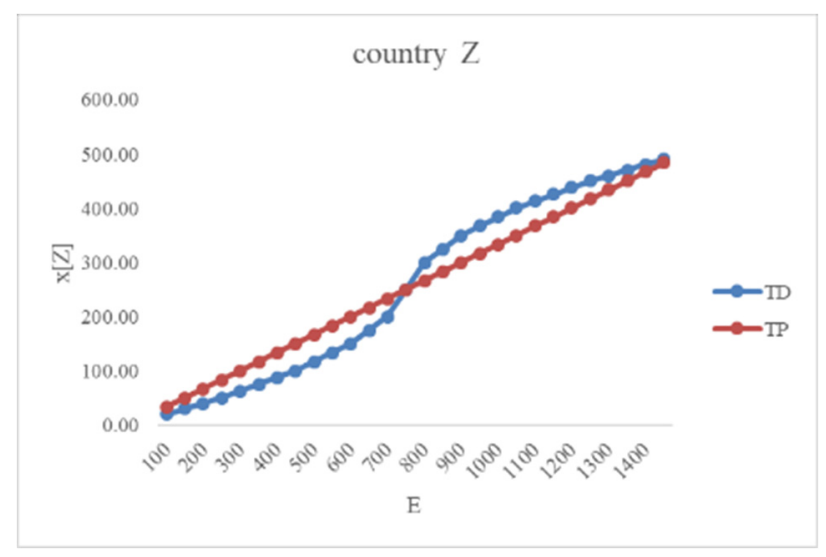

Figure 6 The available amount of vaccine for country Z.

From figures 2-6, we can see that (1) when $E<\frac{D}{2}$, for country $\mathrm{V}, \mathrm{W}$ and $\mathrm{X}$, using $\mathrm{TD}$ can get more vaccines, so TD is better in country $\mathrm{V}, \mathrm{W}$ and $\mathrm{X}$ but TP is better in country $\mathrm{Y}$ and $\mathrm{Z}$ at this time; when $E>\frac{D}{2}$, for country $\mathrm{Y}$ and $\mathrm{Z}$, using $\mathrm{TD}$ can get more vaccines, so TD is better in country $\mathrm{Y}$ and $\mathrm{Z}$ but TP is better in country $\mathrm{V}, \mathrm{W}$ and $\mathrm{X}$ at this time. (2) when $E<\frac{D}{2}$ and the demand of each country grows, TD gradually moves under TP (from figure 2 to figure 6), when $E>\frac{D}{2}$, situation is just the opposite.

According to the ranking of vaccine demand of various countries, it can be found that country $\mathrm{V}$ has the smallest demand, while country $\mathrm{Z}$ has the largest population and the largest demand for vaccine. Based on the concept of protecting the weak, vaccines should be distributed to meet the needs of Country $\mathrm{V}$ as far as possible.

Therefore, when the WHO vaccine supply is in serious shortage (less than half of the total demand), the vaccine supply is obviously unable to meet the needs of all countries, the vaccine should be distributed according to TD. In the late stage of the epidemic, the WHO vaccine supply gradually accumulates and the vaccine is relatively sufficient (more than half of the total demand). At this time, the vaccine should be distributed according to TP.

\section{DISCUSSION}

Allocation of global resources at a global scale is not the first attempt to do so, but the urgency of the allocation of COVID-19 vaccine is far greater than any previous global allocation of resources, thus putting the current global public health cooperation and resource allocation mechanisms to a strict test.

We have proposed an allocation scheme above. But the scheme only considers the population of each country. This is clearly not enough in the current case of the COVID-19. So here we list some of the factors that influence the distribution of vaccines and give some advises to solve these problems.

Figures and tables should be placed either at the top or bottom of the page and close to the text referring to them if possible.

\subsection{Factors Influencing Vaccine Distribution}

\subsubsection{Economic and Cost Factor}

Several foreign media, including $\mathrm{CNN}$ and The Guardian, have reported that high-income countries 
have signed massive purchase agreements with pharmaceutical companies, leaving only a small fraction of the vaccine available for fair distribution around the world.

On the other hand, in terms of research and development, there are differences in the way major countries organize vaccine research and development activities. China's vaccine development has largely drawn on the strengths of the state-run system. But the US is likely to adopt a market-led and company-led model. This determines that in the allocation stage, the "cost" of vaccine products in China and the United States will be considered differently. In the market and company-led research and development mode, "cost" will inevitably be taken as the basic consideration of pricing in the production and distribution stage, and even a considerable proportion of profits and patent fees should be pursued at the same time. These factors, then, must lead to the rich and rich countries benefiting from vaccine products, while the poor in developing countries, especially in poor countries, will be the victims of this factor.

\subsubsection{Political and International Relations Factor}

Our distribution plan needs an official organization or institution to execute it. But for political reasons, the critical global leadership role that the WHO should play in the fight against the COVID-19 has been undermined. However, no existing international organization is in a position to replace the WHO in terms of the global distribution of vaccines going forward. If the major countries are not able to quickly empower WHO action, particularly financially, to meet their share of the burden, vaccine distribution will be severely adversely affected. But that can be hampered by political relations between countries.

From the perspective of the recipients themselves, in the era of sovereign states, any global collective action aimed at global justice must be mediated by the government of the recipient country, allocating resources to the country and then distributing them vertically to its citizens. The basic values of vaccine distribution in recipient countries will then need to align as much as possible with the ethical goals of the global initiative. But a review of past years of aid for global poverty suggests this may not be the case. How to guide recipient countries to do a good job while respecting each other's sovereignty and dignity is both an urgent task and a major factor influencing vaccine distribution.

\subsubsection{Priority Problem}

Priority problem that is, to whom the vaccine product is allocated in the first place. The issue is essentially one of political responsibility. "vaccine nationalism" or "domestic priority" must run counter to the kind of home-level self-sacrifice and concern for strangers in distant places that the global distribution of vaccine products requires. This "custom" and "public opinion" is an important obstacle that must be faced in the next phase of global distribution of vaccines.

Without equitable and equitable global distribution commitments, "vaccine nationalism" or "domestic priority" distribution will make it difficult to contain the spread of COVID-19, even if the vaccine has been developed successfully.

\subsubsection{Demographic Factor}

Equitable distribution of vaccines needs to establish an assessment concept that uses "vulnerability" and "risk" as metrics. When we look at the equitable distribution of vaccines on both domestic and global scales, we first need to see who is the most "vulnerable" to COVID-19 and who is more likely to be exposed to the "risk" of COVID-19. So both domestically and globally, health care workers, the elderly, people with underlying diseases, people with low incomes, coldchain porters, and so on, many of the people who inevitably have to deal with risk sources, of course, should be fairly high in priority.

\subsubsection{Science and Technology Factor}

On the producing countries side, the production and supply capacity and emerging of any new production countries are critical for vaccine distribution. All of these are determined by the level of technology in some way.

Improper storage of vaccines is a major obstacle to the advancement of health immunization. Due to limited refrigeration conditions, many vaccines around the world are discarded every year due to damage. So, the technology of preservation, transportation, and medical care in the recipient countries also need to be considered.

\subsection{Improvement Measures}

\subsubsection{Improving the Transparency in Global Vaccine Distribution}

We cannot rely on the market to break rent-seeking in vaccine distribution. What we can do is to advocate for unprecedented transparency in global vaccine distribution.

Our primary ideological enemy in the equitable distribution of vaccines is the idea that market prices are equivalent to the value of vaccine products. The consequences of market-based distribution of COVID19 would benefit only the rich and the rich, while the 
poor in developing countries, especially in poor countries, would be sacrificed. Any allocation of scarce goods creates all sorts of rent-seeking. Seeking supermonopoly profits is one; the black market is probably the other.

\subsubsection{The Establishment of a Global Vaccine Management Information System}

The official organization or institution who execute the distribution plan is supposed to review the vaccine reservation plan to ensure that the actual vaccine allocation matches the plan and alleviate the problem of poor distribution balance. The establishment of a global vaccine management information system that is easy to use and data aggregated is urgent and necessary. And vaccination information collection, vaccine traceability management and vaccine traceability chain are supposed to reflect in the system. Making the distribution of vaccines intelligent and visual helps to be transparent about the allocation.

\subsubsection{The Idea of Global Solidarity Needs to be Widely Accepted}

A truly equitable distribution of vaccines would begin with a consensus of "global solidarity".

In fact, COVID-19 is an important lesson for humanity. It teaches us a truth, that is, no country, no nation can be immune alone. So, in order to win this battle against the virus, "vaccine nationalism" and "domestic priority" must be corrected and overcome.

\subsubsection{Adopting a "fair priority mode" and Considering Demographic Factors}

Demographic factors and a "fair priority mode" [16] should be paid more attention in the process of distribution.

On vaccine distribution, 19 public health experts in recently in the journal science published a policy report, putting forward the "fair priority mode", a ethical framework based on the three moral principles. This mode includes the harm, the interests of the public relief priority poverty or in countries with lower life expectancy and avoid discrimination in the allocation to some extent [16].

\subsubsection{Improving the Related Technology in Global Vaccine Distribution}

Try to use numerical or parameterized scientific and technological levels as a factor in vaccine distribution and strive to improve the level of related science and technology. The vaccines used at present are prepared by microorganisms themselves or their derivatives, and their properties are easily damaged by unsuitable temperature. Therefore, vaccine products must be stored and transported in an appropriately cold environment [17].

Cold chain transport is a prerequisite for receiving vaccines, and countries and regions should work to improve technology in this area. At the same time, when refrigerated vehicles, cold storage and refrigerators are in use, their operation and temperature should be monitored regularly to ensure the quality of vaccines during transportation and storage.

\section{CONCLUSION}

\section{(1) Summary Main Findings}

In conclusion, for countries with small demands, when the vaccine supply is small $(E<D / 2)$, using Talmud bankruptcy distribution can get the more available vaccine; however, when the vaccine supply is large, using traditional proportional distribution can get more. Moreover, the situation for large population countries is opposite. If the vaccine supply is limited, when the vaccine demand for each country grows, the best plan changes from Talmud bankruptcy distribution to traditional proportional distribution, which means using a traditional distribution plan can get more vaccine when the demand grows. Furthermore, the situation for a large number of vaccines is the opposite. Therefore, suppose we meet the concept of protecting the weak. In that case, the Talmud bankruptcy distribution plan should be used at first, and then use the traditional distribution plan when the supply is relatively sufficient.

The proposed allocation plan only considers the population of each country, which is clearly not enough in a real-world situation. We need to focus on some other factors when dealing with the real vaccine allocation. For example, the different national systems can lead to different allocations in each country, diplomacy can also create a desire to covet or aid other countries' vaccines, and the technology of preserving vaccines is also a crucial factor in distribution. We can try to prepare an elaborate and quite transparent executive plan, consider the "global solidarity", pay attention to distribution priority, use numerical technology to transport, and so on.

\section{(2) Limitation}

The data analysis is based on comparing the use of the Talmud bankruptcy distribution and the traditional proportional distribution to show the different allocation when vaccine is either scarce or sufficient. From the results, we can also see different countries' available vaccine amount by using these two methods at the same time. 
However, the data of this comparing method is not based on the real data, which means the methods of vaccine distribution are analyzed overhead. Therefore, if this analysis can be validated with real-world data and if economic, diplomatic, and technological factors mentioned in the discussion section are considered, a modified version of the distribution scheme will be more likely to meet real-world expectations

\section{REFERENCES}

[1] DB. Coronavirus live update, WORLDOMETER, 21th May 2021. https://www.worldometers.info/coronavirus/

[2] OL. COVAX, Coronavirus, World Health Oraganisation official, 2021. https://www.who.int/initiatives/actaccelerator/covax

[3] OL. COVID-19 vaccine tracker, 21th May 2021. https://covid19.trackvaccines.org/

[4] DB. Mathieu, E., Ritchie, H., Ortiz-Ospina, E. et al. A global database of COVID-19 vaccinations. Nat Hum Behav, 2021. https://ourworldindata.org/covidvaccinations? country $=$ OWID_WRL

[5] R.M. Amer, M. Samir, O.A. Gaber, N.A. EL-Deeb, A.A. Abdelmoaty, A.A. Ahmed, W. Samy, A.H. Atta, M. Walaa, R.H. Anis, Diagnostic performance of rapid antigen test for COVID-19 and the effect of viral load, sampling time, subject's clinical and laboratory parameters on test accuracy, in: Journal of Infection and Public Health, 2021.

DOI:

https://doi.org/10.1016/j.jiph.2021.06.002

[6] A.I. Rodriguez-Perez, C.M. Labandeira, M.A. Pedrosa, R. Valenzuela, J.A. Suarez-Quintanilla, M. Cortes-Ayaso, P. Mayan-Conesa, J.L. LabandeiraGarcia, Autoantibodies against ACE2 and angiotensin type-1 receptors increase severity of COVID-19, in: Journal of Autoimmunity, 2021, 102683.

DOI:

https://doi.org/10.1016/j.jaut.2021.102683

[7] J.N. Yan, L. Luo, J. Rui, S. Yang, B. Deng, Z.Y. Zhao, S.N. Lin, J.W. Xu, Y.Z. Zhu, Y. Wang, M. yang, X.C. Liu, T.L. Yang, W.K.Liu, P.H. Li, Z.Y. Li, C. Liu, J.F. Huang, T.M. Chen, Control measures during the COVID-19 outbreak reduced the transmission of hand, foot, and mouth disease, in: Journal of Safety Science and Resilience, 2021. DOI: https://doi.org/10.1016/j.jnlssr.2021.06.002

[8] S. GUIASU, Revisiting the Ancient Problems of Bankruptcy, in: Contested Garment, and Rights Arbitration, 2008 (2010 Revised).
[9] J. Malkevitch, Resolving Bankruptcy Claims, in: FEATURE COLUMN, March 2005.

[10] T. Fukiharu, Comparison of the Contested Garment Principle and the Proportional Distribution Principle: A Simulation, 2008.

[11] M. Yazdian, G. Rakhshandehroo, M.R. Nikoo, M.G. Mooselu, A.H. Gandomi, T. Honar, Groundwater sustainability: Developing a noncooperative optimal management scenario in shared groundwater resources under water bankruptcy conditions, in: Journal of Environmental Management, Vol. 292, 2021, 112807.

DOI: https://doi.org/10.1016/j.jenvman.2021.112807

[12] Z.P. Tang, J.P. Sun, J. Qian, Railway Emergency Resource Scheduling Strategy Based on Talmud Allocation under Uncertain Condition, in:Systems Engineering 36(04) (2018) 113-120. DOI: CNKI:SUN:GCXT.0.2018-04-014.

[13] Y, Zhang, Y.T. Wang, C. Feng, Equitable distribution model of emergency relief materials, in: Chinese Journal of Systems Science 23 (04) (2015) 79-82+100. DOI: CNKI:SUN:XTBZ.0.2015-04021

[14] M.H. Tsay, C.H. Yeh, Relations among the central rules in bankruptcy problems: A strategic perspective, in: Games and Economic Behavior, vol. 113, 2019, pp. 515-532. DOI: https://doi.org/10.1016/j.geb.2018.10.012

[15] R. J. Aumann, M. Maschler, Game Theoretic Analysis of a Bankruptcy Problem from the Talmud, in: Journal of Economic Theory, vol. 36, 1985, pp. 195-213. DOI: https://doi.org/10.1016/0022-0531(85)90102-4

[16] E.J. Emanuel, G. Persad, A. Kern, A. Buchanan, C. Fabre, D. Halliday, J. Heath, L. Herzog, R.J. Leland, E.T. Lemango, F. Luna, M.S. McCoy, O.F. Norheim, T. Ottersen, G.O. Schaefer, K.C. Tan, C.H. Wellman, J. Wolff, H.S. Richardson, An ethical framework for global vaccine allocation, in: Science, vol. 369, 2020, pp. 1309-1312. DOI: https://doi.org/10.1126/science.abe2803

[17] M.L. Bai, Cold chain transportation and preservation of vaccines, in: Chinese Journal for Clinicians. $05 \quad$ (2006) 4-5. DOI: CNKI:SUN:ZLYS.0.2006-05-002. 